\title{
Analisa Cacat Produk Gasket MW 200N-E1 I dengan Menentukan Faktor Utama Yang Berpengaruh Untuk Optimasi Mutu Produk Di PT. Shin-Etsu Polymer Indonesia Karawang
}

\author{
Ade Suhara \\ Program Studi Teknik Industri, Universitas Buana Perjuangan Karawang \\ Jl. HS. Ronggowaluyo Telukjambe Timur, Karawang 41361 \\ email:ade.suhara@ubpkarawang.ac.id
}

\begin{abstract}
ABSTRAK
Untuk meningkatkan kualitas produk yang dihasilkan maka PT. Shin-Etsu Polymer Indonesia melalui departemen produksi melalui perbaikan-perbaikan dengan mengoptimalkan semua hal yang berpengaruh terhadap mutu produk. Namun untuk bisa mengurangi kecacatan pada produk ini khususnya cacat burr (kelebihan) perlu dilakukan analisa.

Atas dasar itulah dipilih topik analisa cacat untuk mengoptimalkan mutu. Dalam mengumpulkan dan pengolahan data digunakan Desain Eksperimen Taguchi dengan mengunakan Orthogonal Array L $8_{2}{ }^{7}$ suatu matriks keseimbangan dari faktor dan tingkatan faktor. Hasil dari analisa variansi (anova) dapat diketahui faktor-faktor yang berarti (significant) terhadap cacat.

Setelah melakukan pengumpulan data, pengolahan data (dengan metode Taguchi). Maka variabel injection pressure adalah faktor yang berpengaruh dalam proses produksi (perhitungan rata-rata dan rasio $\mathrm{S} / \mathrm{N}$ ).

Setelah penulis melakukan perhitungan dengan menggunakan metode Taguchi Loss Function dapat diketahui bahwa dengan menggunakan kondisi optimum (cacat/rejection dikurangi) maka pabrik akan lebih untung dari sebelumnya, hal ini dapat dilihat dari jumlah kerugian rata-rata yang menurun.pada setting awal Rp.56,37 menjadi Rp. 36,86 dengan setting kondisi optimum. Apabila dalam proses produksi menggunakan setting kondisi optimum maka jumlah rejection rata-rata tidak akan melebihi batas standar rejection yang telah ditetapkan oleh perusahaan yaitu :13\%. Dengan setting kondisi optimum hasil dari hasil pengolahan data yaitu $A_{1} B_{1} C_{2} D_{2}$ $E_{2} F_{1} G_{1}$ terjadi perbaikan mutu produk. Dengan demikian presentasi cacat dapat dikurangi.
\end{abstract}

Kata Kunci : Optimasi, Analisa Cacat, Faktor yang Berpengaruh.

\section{PENDAHULUAN}

Suatu perusahaan seringkali mempunyai masalah dalam mencapai target produksi baik dari segi kuantitas maupun dari segi kualitasnya. Hal ini dapat terjadi karena adanya kerusakan atau cacat yang terjadi pada produk yang dihasilkan. Banyaknya produk yang rusak atau cacat tersebut menyebabkan sebagian hasil produksi terbuang percuma, sehingga target produksi tidak dapat mencapai standar yang telah ditetapkan. Agar hal tersebut tidak terjadi, maka harus dicari faktor-faktor 
yang menimbulkan cacat produk tersebut, dan untuk kemudian dianalisa dan dibuat perbaikannya.

Maka dari itu dilakukan penelitian pada departemen produksi PT. Shin-Etsu Polymer Indonesia yang bergerak di bidang pembuatan wafer shipping box. Pabrik ini mengelola bahan baku berupa thermoplastik elastomer menjadi barang jadi. Bahan baku yang diproses dengan menggunakan injection molding. Bahan baku yang berbnetuk bijih plastik tersebut mengalami berbagai macam tahapan proses seperti melting (fase padat cair), filling (fase cair diinject ke die), cooling (pendinginan), ejection (di pengambilan barang jadi).

\section{TINJAUAN PUSTAKA}

\section{Arti dan Peranan Pengendalian Mutu}

Pengertian mutu menurut Taguchi "Memberikan/menyediakan produk dan jasa untuk memenuhi keinginan pelanggan dengan harapan nilai yang lebih dari produk atau jasa, pada suatu harga yang menggambarkan nilai pelanggan”.

Derajat kegunaan produk dan kemudahan pemeliharaan yang masuk baik harus ditetapkan, sehingga produk tersebut harus mempunyai kemampuan layanan dan kemudahan pemeliharaan yang tepat sepanjang daur hidupnya. Produk tersebut harus mempunyai penampilan yang sesuai dengan persyaratan pelanggan, dengan demikian ia harus mempunyai daya tarik.

\section{Klasifikasi Karakteristik Mutu}

Klasifikasi mutu adalah suatu obyek yang penting dari produk atau proses. Biasanya juga disebut dengan karakteristik fungsional atau variabel respon. Karakteristik mutu dapat diklasifikasikan menurut nilai targetnya, yaitu : Nominal the best, Small the best, Large the best, Signed target \& Classified Attribute.

\section{Pengendalian Mutu dengan Model Statistik}

Metode statistik merupakan alat yang efektif untuk memperbaiki proses produksi dan mengurangi kerusakan produk yang terjadi. Harus diingat metode statistik hanya merupakan alatbyang tidak akan bekerja dengan baik bila digunakan secara kurang tepat.

\section{Proses Desain Eksperimen}

\section{Prinsip Dasar Eksperimen}

Ada tiga prinsip dasar dari desain eksperimen, yaitu : replication, randomization dan blocking.

\section{Tujuan Eksperimen}

Tujuan eksperimen adalah untuk mengetahui bagaimana mereduksi dan mengontrol perbedaan dari produk atau proses, sebagai akibatnya keputusan yang dibuat harus 
diperlihatkan pada parameter-parameter yang berhubungan dengan unjuk kerja produk atau proses.

\section{Dasar Ekperimen}

Dasar eksperimen adalah dengan menggunakan deret orthogonal (orthogonal array). Penggunaan deret orthogonal hanya merupakan salah satu metodologi untuk desain eksperimenya, tetapi lebih fleksibel dalam menyesuaikan berbagai situasi.

\section{Jenis - jenis Desain Metode Eksperimen}

Terdapat 4 jenis metode desain ekperimen yaitu : Metode Klasik (full factorial design), Metode Taguchi, Metode Shainin, Metode Algoritma Genetika.

\section{Metode Taguchi}

Definisi mutu menurut Taguchi, "Mutu suatu produk adalah jumlah kerugian minimum yang ditanamkan oleh produk pada masyarakat sejak produk tersebut dikirimkan".

Dalam metode Taguchi kualitas dapat dicapai dengan keseragaman produk untuk karakteristik kualitasnya daripada yang dicapai jika nilai karakteristik kualitas hanya memenuhi spesifikasi kualitas secara sederhana.

\section{METODOLOGI PENELITIAN}

\section{Langkah - langkah Penelitian}

1. Identifikasi Masalah

Masalah yang terjadi yaitu terdapat beberapa variabel utama yang berpengaruh terhadap keberhasilan suatu proses injection molding. Penyimpangan terhadap variabel-variabel yang berpengaruh tersebut dapat menimbulkan cacat produksi.

2. Studi Literatur

Hasil penelitian ini berupa informasi yang bersifat teoritis yang digunakan sebagai pedoman dalam penelitian yang dilakukan dan sebagai bahan perbandingan dengan hasil yang telah dicapai.

3. Model Analisa

Model analisa yang di pakai yaitu dengan menerapkan metode Taguchi

4. Pengmpulan Data

Data yang diperlukan untuk memecahkan masalah ini adalah Holding Perssure, Injection Speed, Holding Time, Injection end Position, Injection Pressure, Clamping Pressure dan Metering Time.

5. Pengolahan Data

Data-data yang didapat dalam pengumpulan data diolah dengan metoda Taguchi, adapun pengolahan-pengolahan yang dilakukan pada data-data 
tersebut adalah rata- rata dari hasil ekperimen, rata - rata keseluruhan hasil eksperimen dan table hasil eksperimen.

6. Analisis dan Pembahasan

Setelah diperoleh hasil yang diinginkan, selanjutnya hasil tersebut perlu dianalisa. Ada beberapa analisa yang perlu dilakukan dalam hal ini, yaitu Analisa data untuk rasio $\mathrm{S} / \mathrm{N}$, Pemecahan masalah untuk rasio $\mathrm{S} / \mathrm{N}$, Perhitungan Lost Function I dan Perhitungan Lost Function II.

7. Kesimpulan dan Saran

Dari hasil pengumpulan dan pengolahan data, perhitungan dan analisa yang telah dilakukan selanjutnya dapat diambil kesimpulan.

\section{Langkah - langkah dalam menentukan hasil mutu dengan menggunakan metode Taguchi}

1. Rata-rata dari hasil eksperimen $\left(\overline{\mathrm{y}}_{1}\right) . \quad \overline{\mathrm{y}}_{1}=\frac{\sum \mathrm{X}_{1}}{\mathrm{nx}_{1}}$

\begin{tabular}{|l|l|l|l|l|l|l|l|}
\hline & $\mathrm{A}$ & $\mathrm{B}$ & $\mathrm{C}$ & $\mathrm{D}$ & $\mathrm{E}$ & $\mathrm{F}$ & $\mathrm{G}$ \\
\hline Tingkat 1 & $* * *$ & $* * *$ & $* * *$ & $* * *$ & $* * *$ & $* * *$ & $* * *$ \\
\hline Tingkat 2 & $* * *$ & $* * *$ & $* * *$ & $* * *$ & $* * *$ & $* * *$ & $* * *$ \\
\hline Selisih & $* *$ & $* *$ & $* *$ & $* *$ & $* *$ & $* *$ & $* *$ \\
\hline Urutan & $*$ & $*$ & $*$ & $*$ & $*$ & $*$ & $*$ \\
\hline
\end{tabular}

2. Rata-rata keseluruhan hasil eksperimen $(\overline{\mathrm{y}}) \cdot \overline{\mathrm{y}}=\frac{\sum \mathrm{x}}{\mathrm{nx}_{1}}$

3. Tabel hasil eksperimen

4. Total dari jumlah Kuadrat (ST)

$$
\mathrm{ST}=\Sigma \mathrm{y}^{2}
$$

5. Jumlah kuadrat rata-rata $(\mathrm{Sm})$

$$
\mathrm{Sm}=\mathrm{n} \cdot \mathrm{y}^{2}
$$

6. Jumlah kuadrat dari setiap faktor $(\mathrm{Sq})$

$$
\mathrm{Sq}_{\mathrm{x}}=\mathrm{n}_{\mathrm{x} 1} \times \mathrm{X}_{1}^{2}+\mathrm{n}_{\mathrm{x} 2} \times \mathrm{X}_{2}^{2}-\mathrm{Sm}
$$

7. Jumlah kesalahan jumlah kuadrat $(\mathrm{Se})$

$$
\mathrm{Se}=\mathrm{ST}-\mathrm{Sm}-\mathrm{SA}-\mathrm{SB}-\mathrm{SC}-\mathrm{SD}-\mathrm{SE}-\mathrm{SF}-\mathrm{S}
$$

8. Rata-rata jumlah kuadrat $(\mathrm{Mq})$ :

$$
\mathrm{Mq}_{\mathrm{X}}=\frac{\mathrm{Sq}_{\mathrm{X}}}{\mathrm{v}_{\mathrm{X}}}
$$

9. Menentukan F-ratio (F) : 


$$
\mathrm{F}_{\mathrm{X}}=\frac{\mathrm{Mq}_{\mathrm{X}}}{\mathrm{S}_{(\mathrm{e})}}
$$

10. Deviasi jumlah kuadrat yang tidak berpengaruh (Sq')

$$
\mathrm{Sqx}^{\prime}=\mathrm{Sqx}-\left(\mathrm{v}_{\mathrm{x}} \mathrm{x} \mathrm{Mq}_{(\mathrm{e})}\right)
$$

11. Menghitung kontribusi persen $(\rho \%)$ :

$\rho \mathrm{x}=\frac{\mathrm{Sqx}^{\prime}}{\mathrm{St}} \times 100 \%$

12. Menentukan batas kepercayaan dengan tingkat faktor $(\mathrm{CI})$ :

$\mathrm{CI}=\sqrt{\mathrm{F}_{\alpha, \mathrm{v} 1, v 2} \chi \mathrm{V}_{\mathrm{e}} \chi \frac{1}{\mathrm{n}}}$

13. Nilai rata-rata proses yang diberikan data $(\mu)$

$$
\begin{array}{lll}
\mu_{\mathrm{x} 1}=\mathrm{X} 1 \pm \mathrm{CI} & \text { atau } & \mu_{\mathrm{x} 2}=\mathrm{X} 2 \pm \mathrm{CI} \\
\mathrm{X} 1-\mathrm{CI} \leq \mu_{\mathrm{A} 1} \geq \mathrm{X} 1+\mathrm{CI} & \text { atau } & \mathrm{X} 2-\mathrm{CI} \leq \mu_{\mathrm{A} 1} \geq \mathrm{X} 2+\mathrm{CI}
\end{array}
$$

Dimana : $X=A, B, C, D, F, G$

\section{PENGUMPULAN DAN PENGOLAHAN DATA}

\section{Pengumpulan Data}

Data yang dibutuhkan dalam menentukan hasil mutu dengan menggunakan metode Taguchi yaiitu sebagai berikut :

1. Holding Pressure

2. Injection Speed

3. Holding Time

4. Injection End Position

5. Injection Preassure

6. Clamping Pressure

7. Metering Time

\section{Pengolahan Data}

Pengolahan data dalam penelitian ini yaitu sebagai berikut :

1. Data perhitungan rasio $\mathrm{S} / \mathrm{N}$ Rejection

Dengan menggunakan rumus MSD untuk karakteristik smaller the better, yaitu :

- $\mathrm{MSD}=\left\{\left(\mathrm{Y}_{1}-\mathrm{m}\right)^{2}+\left(\mathrm{Y}_{2}-\mathrm{m}\right)^{2}\right\} / 2$

- $\mathrm{S} / \mathrm{N}=\eta=-10 \log (\mathrm{MSD})$ tabel 4.8

Yang dihitung untuk masing-masing trial, diperoleh hasil seperti pada

Tabel 4.8 Tabel Rasio S/N 


\begin{tabular}{|l|l|l|l|l|}
\hline $\begin{array}{l}\text { No } \\
\text { Percobaan }\end{array}$ & Y1 & Y2 & MSD & $\eta(\mathrm{db})$ \\
\hline 1 & 1,4 & 1,5 & 2.05 & $-3,23252$ \\
2 & 1,0 & 1,2 & 1.22 & $-0,8636$ \\
3 & 1,6 & 1,7 & 2,725 & $-4,35367$ \\
4 & 1,1 & 1,1 & 1,21 & $-0,82785$ \\
5 & 1,2 & 1,2 & 1,44 & $-1,58362$ \\
6 & 1,2 & 1,3 & 1,565 & $-1,9454$ \\
7 & 1,4 & 1,4 & 1,96 & $-2,92256$ \\
8 & 1,5 & 1,6 & 2,25 & $-3,52183$ \\
\hline
\end{tabular}

2. Perhitungan faktor yang berpengaruh (ANOVA) untuk rasio $\mathrm{S} / \mathrm{N}$ Peritungan Rasio S/N untuk mencari difference (perbedaan) dan ranking (peringkat) :

$$
\begin{aligned}
\overline{\mathrm{A} 1} & =\frac{\mathrm{Y} 1+\mathrm{Y} 2+\mathrm{Y} 3+\mathrm{Y} 4}{4} \\
& =\frac{-3,23+0,863+-4,353+0,827}{4} \\
& =-2,319 \\
\mathrm{~A} 2 & =\frac{-1,583+-1,945+-2,992+-3,521}{4} \\
& =-2,493
\end{aligned}
$$

(Lakukan perhitungan yang sama dengan faktor yang berbeda)

Dari hasil perhitungan rasio $\mathrm{S} / \mathrm{N}$ di atas maka, didapat tabel seperti di bawah ini

Tabel 4.9 faktor yang berpengaruh untuk rasio $\mathrm{S} / \mathrm{N}$

\begin{tabular}{|l|l|l|l|l|l|l|l|}
\hline & $\mathrm{A}$ & $\mathrm{B}$ & $\mathrm{C}$ & $\mathrm{D}$ & $\mathrm{E}$ & $\mathrm{F}$ & $\mathrm{G}$ \\
\hline Level 1 & - & - & - & - & - & - & - \\
& 2,319 & 1,906 & 2,635 & 3,023 & 3,263 & 2,291 & 2,232 \\
\hline Level 2 & - & - & - & - & - & - & - \\
& 2,493 & 2,906 & 2,177 & 2,177 & 1,549 & 2,251 & 2,580 \\
\hline Difference & 0,173 & 1.000 & 0,457 & - & - & 0,229 & 0,348 \\
& & & & 1,233 & 1,713 & & \\
\hline Ranking & 7 & 3 & 4 & 2 & 1 & 6 & 5 \\
\hline
\end{tabular}


- Dari tabel di atas dapat mengenalisa bahwa faktor E (Injection Pressure) mempunyai pengaruh paling besar pada rejection (\%). Maka faktor E (Injection Pressure) harus lebih diperhatikan pada pengamatan berikutnya.

- Kondisi optimal untuk masing-masing faktor dipilih berdasarkan tabel di atas dengan menggunakan perhitungan rata-rata maka kondisi optimumnya adalah:

$\mathrm{A} 1-\mathrm{B} 1-\mathrm{C} 2-\mathrm{D} 2-\mathrm{E} 2-\mathrm{F} 1-\mathrm{G} 1$

3. Perhitungan Loss Function I

Dilakukan data - data hasil pengujian Rejection yang diperoleh sesuai dengan kedaan mesin pada saat bekerja.

Tabel 4.11 Data Hasil Rejection

\begin{tabular}{|l|l|}
\hline Percobaan & $\begin{array}{l}\text { Rejection } \\
(\%)\end{array}$ \\
\hline 1 & 1,3 \\
2 & 1,6 \\
3 & 1,5 \\
4 & 1,1 \\
5 & 1,4 \\
6 & 1,1 \\
7 & 1,7 \\
8 & 1,7 \\
9 & 1,6 \\
10 & 1,4 \\
\hline
\end{tabular}

囚 Berat $1 \mathrm{sak} /$ pak bahan baku $=25 \mathrm{~kg}$

囚 Harga $1 \mathrm{sak} /$ pak bahan baku = Rp. 150.000,-

囚 $\operatorname{Harga} 1 \mathrm{~kg}=\frac{\mathrm{Rp} \cdot 150 \cdot 000,-}{25}=\mathrm{Rp} \cdot 6.000$,-

Harga 1 gram = Rp. 6,-

$\triangle \quad$ Produk yang dihasilkan berat $=28$ gram

囚 Biaya bahan untuk 1 pcs $=\frac{\text { berat seluruh produk }}{\text { cavity }}$

$=\frac{28 \text { gram }}{2}=$ Rp. 14

囚 Harga produk = harga 1 gram/pcs bahan baku $\mathrm{x}$ berat produk

$=$ Rp. 14 x 28 gram

$=$ Rp. $392 /$ gram 


\section{ANALISA DAN PEMBAHASAN Analisa}

1. Analisa data untuk faktor rata - rata

Faktor-faktor mana yang berarti (significant) dengan membandingkan hasil Fratio dengan F-tabel. Jika F-ratio > F-tabel maka faktor tersebut merupakan faktor yang berarti (significant) dan jika F-ratio < F-tabel maka faktor tersebut bukan merupakan faktor yang berarti (insignificant). Dari tabel Anova di atas, Fratio untuk Faktor Injection Pressure adalah \pm 36,98 dan dari tabel $\mathrm{F}$ dengan memakai $\alpha=0,01, v_{1}=1, v_{2}=11$ didapat $\mathrm{F}_{0,01 ; 1 ; 11}=9,65$. Dari hasil tersebut diketahui bahwa F-ratio hasil perhitungan lebih besar dari F-tabel, oleh karena itu faktor Injection Pressure merupakan sebuah faktor yang berarti (significant), sama halnya dengan faktor Injection Speed dan Injection End Position merupakan faktor yang berarti (significant).

2. Analisa Data untuk Rasio $\mathrm{S} / \mathrm{N}$

Faktor Holding Pressure ,Holding Time ,Clamping Pressure dan Metering Time hanya memberi pengaruh sedikit jadi agar keadaan demikian diinginkan maka komposisi larutan harus tetap dijaga sedemikian rupa.

3. Analisa Data Percobaan Konfirmasi Dari Loss Function I dan II

Setelah melakukan percobaan konfirmasi, maka dapat dilihat adanya perbaikan dari Loss Function I ke Loss Function II. Yaitu jumlah kerugian rata-rata pada kondisi awal adalah Rp.491,27. Sedangkan jumlah kerugian rata-rata tiap unit pada kondisi optimum adalah Rp.321,25.

\section{Pembahasan}

1. Analisa data untuk faktor rata - rata

Dengan menggunakan setting mesin pada kondisi optimum seperti yang terdapat pada gambar 5.1 diatas maka dapat mengurangi kerugian dari sebesar Rp.491,27 Pada setting mesin kondisi awal, menjadi sebesar Rp 321,25. Setelah digunakan setting mesin pada kondisi optimum.

2. Analisa Data untuk Rasio S/N

Tingkat pengaruh faktor E Injection Pressure jika dinyatakan dalam persen \pm 47,39\% (Tabel Anova). Begitu juga faktor Injection Speed dan faktor Injection End Position yang mempunyai pengaruh masing-masing $\pm 14,99 \%$ dan $23,73 \%$.

3. Analisa Data Percobaan Konfirmasi Loss Function I dan II Dari kesimpulan dapat kita lihat bahwa dengan perhitungan perbedaan harga telah mengakibatkan adamya perbaikan Loss Function yaitu Rp.170,02.

\section{KESIMPULAN}

1. Setelah melakukan pengumpulan data, pengolahan data (dengan metode Taguchi). Maka variabel injection pressure adalah paktor yang berpengaruh dalam proses produksi (perhitungan rata-rata dan rasio $\mathrm{S} / \mathrm{N}$ ).

2. Setelah penulis melakukan perhitungan dengan menggunakan metode Taguchi Loss Function dapat diketahui bahwa dengan menggunakan kondisi optimum 
(cacat/rejection dikurangi) maka pabrik akan lebih untung dari sebelumnya, hal ini dapat dilihat dari jumlah kerugian rata-rata yang menurun.pada setting awal Rp.491,27 menjadi Rp. 321,25 dengan setting kondisi optimum.

3. Apabila dalam proses produksi menggunakan setting kondisi optimumaka jumlah rejection rata-rata tidak akan melebihi batas standar rejection yang telah ditetapkan oleh perusahaan yaitu :13\%.

\section{DAFTAR PUSTAKA}

L. Grant Eugene and Leavenworth Richard, Pengendalian Mutu Statistik, Edisi keenam, Boston : Mc Graw Hill Inc, 1988.

Mad Hau S, Phadke, Qulity Engineering Using Robust Design, Prentice, Hall int, Edition, 1989.

R. Hastono, Bahan Industri, Jilid 1. Jakarta : Gramedia.

Ross, Phillip J. Taguchi Technique for Quality Engineering, New York : McGraw Hill Book Company, 1996.

Sriati D. Teknologi Mekanik, Jakarta : Erlangga, 1985.

Winarno. Penerapan Metode Taguchi pada Mc Deinking Pulp. Di PT Pindodeli Pulp and Paper Mills Karawang. 